\title{
$\mathrm{UCC}$ 제작자를 위한 UCC 추천 시스템 설계와 메타데이터 구성
}

송 주 홍a), 문 남 미 ${ }^{\text {a }}$

\section{Design of Recommender System and Metadata Construction for UCC producer}

\author{
Ju-Hong Song ${ }^{\text {a) }}$ and Nammee Moon ${ }^{\text {a) }}$
}

요 약

다양한 UCC를 제작하기 위해서는 UCC 소비자들을 위한 추천 서비스와는 차별화된 UCC 제작자의 저작권과 제작 목적 등을 고려 한 추천서비스가 필요하다. 본 논문에서 설계되어진 추천 시스템은, UCC 제작자의 UCC 뷰 히스토리와 제작 목록 등을 기반으로, $\mathrm{UCC}$ 제작자가 활용한 $\mathrm{UCC}$ 와 유사도가 높은 $\mathrm{UCC}$ 를 맞춤형으로 추천하여 제작할 때 사용가능 하도록 한다. 추천 시스템은 크게 선 호태그 기반 필터링, 선호 $\mathrm{UCC}$ 를 제작할 때 사용한 UCC 필터링, 피어슨 공식을 이용한 추천 UCC 생성과정으로 나눠진다. 본 논문 의 추천시스템은 $\mathrm{UCC}$ 를 제작할 때 활용한 $\mathrm{UCC}$ 들의 정보가 필요하다. 이를 위해 기존의 메타데이터에 $\mathrm{UCC}$ 를 제작할 때 활용한 $\mathrm{UCC}$ 의 정보를 기재할 수 있도록 레퍼런스(Reference) 요소를 추가하였다. 본 논문에서 제안하는 추천시스템을 활용한다면, UCC 제 작에 있어 보다 효율적이고 편이성 높은 제작자 맞춤형 UCC 추천 서비스를 제공할 수 있을 것이다.

\begin{abstract}
In order to produce the variety of UCC, the recommendation service is required which considers the copyright of UCC producer discriminated from one for UCC consumers and the purpose of its production. The recommender system designed in this thesis enables UCC which is much similar to one UCC producer utilizes to be used with custom-made when recommending and producing based on UCC view history and production list, etc. of its producer. The recommender system is largely divided into filtering based on the preferred tag, UCC filtering used when producing the preferred UCC and creating process of recommended UCC using the Pearson formula. The recommender system in this thesis requires the data which were used when producing UCC. For that, we added the reference factor so that the data of UCC which were utilized when producing UCC into the existing metadata can be recorded. If the recommender system suggested in this thesis is used, the more effective and convenient UCC recommendation services with custom-made for producers can be provided.
\end{abstract}

Keyword : UCC producers, Recommender system, Metadata, Reference, Personalize

a) 호서벤처전문대학원

Hoseo Graduate School of Venture

₹ 교신저자 : 문남미 (mnm@hoseo.edu)

※이 논문은 2010 년도 정부(교육과학기술부)의 재원으로 한국과학재단의 지원을 받아 수행된 연구임(No.2010-0000487).

· 접수일(2010년12월30일), 수정일(2011년3월3일), 게재확정일(2010년3월3일)

\section{I. 서 론}

웹 2.0 의 대표적인 산물로 일컫는 $\mathrm{UCC}$ 는 사용자들이 직접 제작, 소비하며 또 다른 부가가치를 창출해 내는 콘 
텐츠이다. UCC는 제작이 용이하고, 전달력이 빨라 파급력 이 크다는 장점을 가지고 있으며, 동영상 검색 서비스, 동 영상 전문 포탈 사이트, 동영상 블로그 등의 서비스가 성 황하면서 개인적, 문화적 특성들을 바탕으로 급격히 성장 하였다 ${ }^{[1][2][3]}$.

YouTube, 판도라TV등의 UCC 전문 서비스 업체들은 시 장 점유율을 높이기 위해 차별화된 서비스들을 제공하고 있으며, 가장 대표적인 서비스로 사용자 편의성 제고를 위 한 UCC 추천서비스를 들 수가 있다. 하지만 이는 UCC 소 비자들을 위한 서비스로써, UCC 제작자를 위한 추천 서비 스의 필요성도 고려해봐야 할 것이다. 이를 위해선 저작권 을 보호받으려는 $\mathrm{UCC}$ 제작자와 기존의 $\mathrm{UCC}$ 를 활용하려 는 타 제작자라는 서로 다른 사용자 관점 또한 고려해 볼 필요성이 있다 ${ }^{[4][5]}$.

이에 본 논문에서 제안하는 추천서비스는 기존 $\mathrm{UCC}$ 소 비자 중심의 추천서비스와는 달리 저작권과 제작 편이성을 고려하여 차별화 된 $\mathrm{UCC}$ 제작자 중심의 개인화 추천 서비 스를 제공하는데 목적을 두고 있다. 이를 위해 UCC 콘텐츠 를 제작할 때 발생되는 저작권 문제를 효과적으로 해결하 기 위해 레퍼런스 요소를 추가하여 메타데이터를 구성하 였으며, $\mathrm{UCC}$ 의 메타데이터 정보를 활용한 협업 필터링 기 반의 추천 시스템을 제안하고자 한다.

\section{II. 관련연구}

\section{UCC}

$\mathrm{UCC}$ 는 웹이 등장하면서 존재하였으나 웹에 참여, 공유, 개방의 특징이 두드러지게 나타나면서 시장이 폭발적으로 증가하였다. $\mathrm{UCC}$ 는 제작이 용이하고, 전달력이 빨라 파급 력이 큰 장점을 가져 비즈니스 및 다양한 분야와의 융합이 활발히 이루어지고 있다 ${ }^{[6]}$. UCC는 매체에 따라 텍스트, 오 디오, 이미지, 비디오, 패키지 형태로 분류할 수 있으며 내 용에 따라서는 인포메이션, 엔터테이너먼트, 비지니스로 분류를 할 수 있다 ${ }^{[6[7]}$. 초기의 UCC 서비스가 UCC 제작자 가 사용자가 찍은 동영상을 동영상 전문 포탈 등에 올리는 형식이었다면, 현재는 YouTube나 판도라TV, 싸이월드 등 서비스 업체에서 UCC 제작 툴을 제공하고 있다.

이는 사용자가 텍스트나 이미지 형식의 파일을 조합하여 동영상 형태로 쉽게 변환할 수 있도록 하는 기능 뿐 아니라 $\mathrm{UCC}$ 를 패러디하거나 조합하는 등의 $\mathrm{UCC}$ 를 활성화에 기 여하고 있다. 하지만 UCC 제작을 위한 참조 콘텐츠의 제공 은 부족한 실정이며 이에 따라 사용자가 $\mathrm{UCC}$ 를 제작하기 위해 참조 콘텐츠를 찾는데 많은 노력과 시간이 필요하다. 더불어 $\mathrm{UCC}$ 제작에 참조한 콘텐츠에 대한 저작권 관리도 투명하게 이루어지기 어렵다.

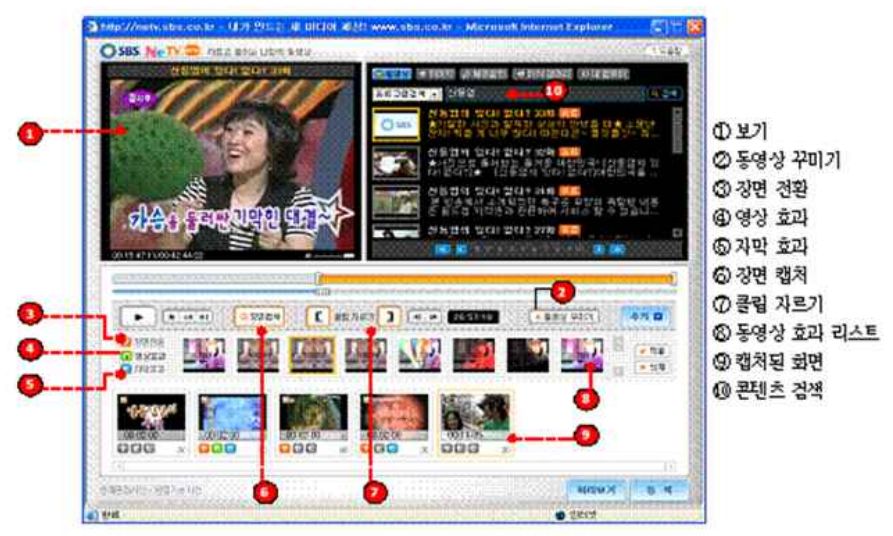

그림 1. SBSi의 NeTV베타를 이용한 방송 콘텐츠 편집 장면

Fig. 1. Editing of broadcast content using the NeTV beta SBSi 


\section{2. 추천서비스}

추천서비스는 사용자의 행위 및 정보를 기반으로 선호도 를 예측하여 사용자의 선호도가 고려된 아이템을 제안하는 것을 말한다 ${ }^{[8][9]}$. 최근 개인화 서비스의 중요성이 매우 높아 지고 있으며 비즈니스와 직접적으로 연계가 가능하기 때문 에, 다양한 분야에서 추천서비스에 대한 여러 연구가 활발 하게 진행되고 있다. 이미 웹 서비스의 다양한 분야에서도 추천서비스가 제공되고 있으며, 기존의 추천서비스들은 주 로 고객들의 프로파일과 행위, 아이템의 메타데이터 등을 이용하여 사용자들에게 서비스를 제공한다. 전자상거래에 서는 고객 구매패턴, 정보를 바탕으로 상품을 추천하며, 웹 서비스에서는 사용자의 기본정보, 서비스 내역 등의 데이 터를 수집하여 사용자가 선호할 만한 콘텐츠들을 주로 추 천하게 된다. 이렇듯 추천서비스는 사용자를 고려한 맞춤 형 서비스를 목적으로 두고 있기 때문에, 어떠한 대상에게 무엇을 추천할 것인지를 고려해야 하며, 사용자의 행위 및 정보를 유추할 수 있는 데이터와 이를 가공할 수 있는 추 천 기법들이 필요하다. 대표적인 추천 기법은 협업기반 (Colleborative-based), 내용기반(Contents-based), 하이브리 드기반(Hybrid-based)이 있다 ${ }^{[11][12]}$.

협업 기반 필터링 기법은 고객들의 프로파일 정보를 바 탕으로 아이템에 대한 목표고객의 평가치와 유사그룹 고객 의 평가치를 바탕으로 목표고객이 선호할만한 아이템을 추천하는 기법이며, 신규 사용자, 확장성, 성능에 관한 한계 점을 가지고 있다.

내용 기반 필터링 기법은 소비한 아이템들에 대한 평가를 종합하여, 좋은 평가를 받은 아이템과 비슷한 특성을 보이는 새로운 아이템을 추천해주는 방식으로 평가치가 없는 새로 운 아이템, 희박성, 확장성에 관한 한계점을 가지고 있다. 하이브리드기반 기법은 내용기반과 협업기반방식 혹은 아이템 기반과 사용자 기반 결합 방식을 혼합하여 사용한 기법이다.

본 연구에선 $\mathrm{UCC}$ 제작자의 $\mathrm{UCC}$ 선호도와 제작된 $\mathrm{UCC}$ 의 메타데이터 정보를 기반으로 하여 협업 필터링 기반의 추천 시스템을 구성하고자 한다.

\section{3. 메타데이터}

메타데이터(Metadata)는 자원의 속성을 기술하는 데이 터로써 도서, 지도, 웹, 멀티미디어 등 다양한 기술대상에 적용할 수 있다. 멀티미디어와 관련된 대표적 메타데이터 의 예로는 더블린코어(Dublin Core), MPEG-7, SOiVA (Service Oriented interactive Video Application), UCI (Universal Content Identifier) 등이 있다 ${ }^{[13]}$. 더블린코어는 최초의 메타데이터 표준으로써 동영상, 소리, 이미지 등 디 지털 매체들에 널리 사용되고 있으며 크게 콘텐츠 기술요 소, 지적 속성요소, 물리적 기술요소의 세 범주로 구별되며, 15 개의 기본요소를 가지고 있다. 더블린코어는 단순한 형 식을 취하고 있어 비용이 적게 들고 상호 운용성이 높으나 다양한 정보 및 기능을 제공하지 못한다는 단점이 있다 ${ }^{[14]}$. MPEG-7은 멀티미디어의 일부에 대한 요소를 제공하여 내 용기반 검색이 가능하도록 하는 특징을 가지고 있으며 디 스크립터, 기술체계, 기술정의언어의 주요 요소를 사용한 다 ${ }^{[14][15]}$. SOiVA는 양방향 동영상을 기반으로 하는 메타데 이터이다. 효과적 콘텐츠 관리를 위하여 identifier를 유일한 식별자로 두고 13 가지의 메타데이터 요소를 가지고 있다 ${ }^{[16]}$. UCI는 자원의 효율적 유통 활용을 목적으로 한 메타데 이터로써 자원에 유일한 코드를 부여하는 특징을 가지고 있다. UCI 또한 SOiVA와 마찬가지로 identifier를 가지고 콘텐츠를 관리하며, 한국정보사회진흥원에서 부여하는 고 유한 자원 식별자를 함께 사용한다. UCI는 총 9개의 메타 데이터 요소를 가지고 있다 ${ }^{[16][17]}$.

\section{III. 본론}

\section{1. 레퍼런스 UCC 추천 시스템의 개요}

레퍼런스 $\mathrm{UCC}$ 는 $\mathrm{UCC}$ 를 제작할 때 활용한 $\mathrm{UCC}$ 들을 일 컫는다. 본 연구는 이 레퍼런스 UCC들을 활용한 추천 시스 템을 통해 제작자의 선호도와 저작권이 고려된 추천 $\mathrm{UCC}$ 리스트를 제공함으로써, $\mathrm{UCC}$ 제작자의 콘텐츠 제작 편의 성을 높이고 저작권 문제를 해결한 제작자 맞춤형 $\mathrm{UCC}$ 추 


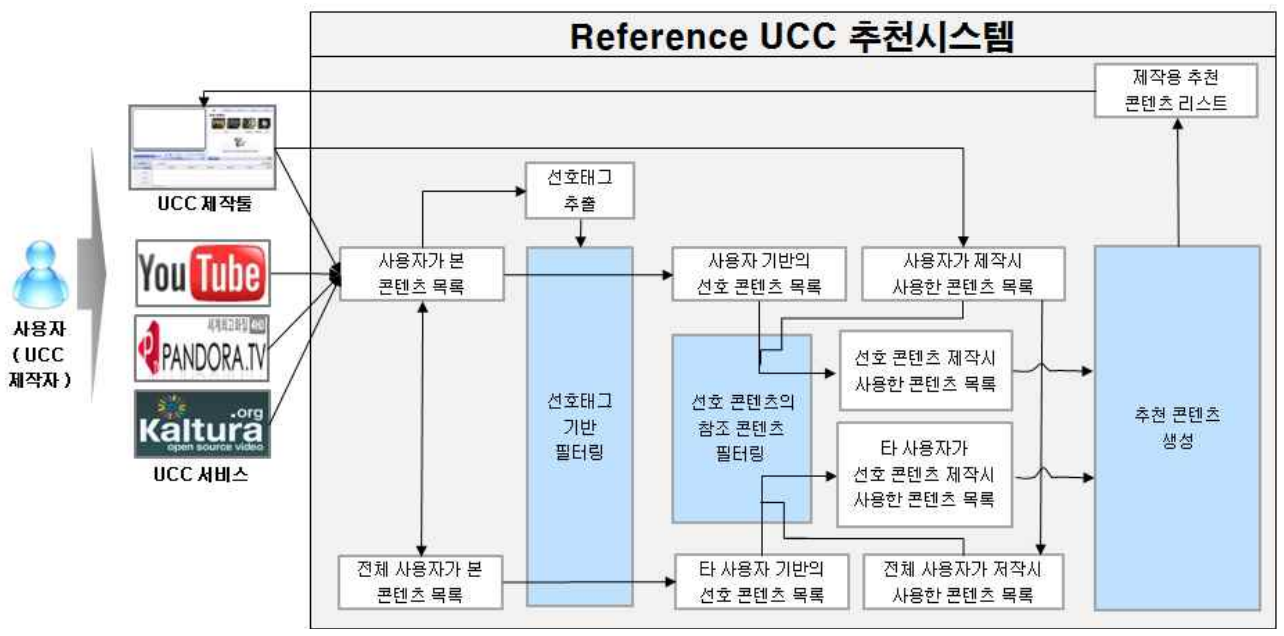

그림 2. UCC를 제작할 때 사용하는 UCC 추천시스템의 흐름 ${ }^{[9]}$

Fig. 2. The flow of recommender system using when UCC create

천서비스를 제공한다는 것에 목적을 두고 있다.

그림 2는 레퍼런스 $\mathrm{UCC}$ 추천시스템의 동작 구성도이다. 추천 시스템은 $\mathrm{UCC}$ 제작자들이 감상한 $\mathrm{UCC}$ 와 레퍼런스 $\mathrm{UCC}$ 의 데이터들을 가공하여 제작자에게 제작용 추천 $\mathrm{UCC}$ 목록을 제공한다. 데이터 가공과정은 크게 선호태그 기반 필터링, 선호 $\mathrm{UCC}$ 를 제작할 때 사용한 $\mathrm{UCC}$ 필터링, 선호 UCC 생성 알고리즘을 통한 추천 리스트 생성과정으 로 나눠지게 되며 각 과정에 대한 세부 설명은 다음과 같다.

선호 태그 기반 필터링 과정에선 추출된 $\mathrm{UCC}$ 제작자의 선호태그를 이용해 선호태그 기반의 UCC 그룹을 생성하는 단계이다. 사용자가 보거나 제작할 때 활용한 $\mathrm{UCC}$ 들의 태 그에서 빈도분석기법을 이용해 선호태그를 추출한 후 선호 태그가 과반수이상 일치 하는 UCC들을 그룹으로 묶어주는 과정이다.

선호 $\mathrm{UCC}$ 의 레퍼런스 $\mathrm{UCC}$ 필터링 과정은 각각 사용자 와 타사용자 기반의 선호 UCC 목록과 레퍼런스 UCC 목록 을 이용해 선호 $\mathrm{UCC}$ 의 레퍼런스 UCC 목록을 만들어 내는 단계로 이 단계에서 만들어진 UCC 목록은 추천 레퍼런스 $\mathrm{UCC}$ 생성 과정에서 사용된다. 이 과정에선 레퍼런스 UCC 의 정보가 필요하며 이를 위해 본 연구에선 기존의 메타데 이터에 레퍼런스 메타데이터를 추가하여 메타데이터를 구 성하였다.
추천 UCC 생성 과정은 제작자에게 추천할 레퍼런스 $\mathrm{UCC}$ 목록을 생성하는 단계이다. 이를 위해 식 (1)과 식 (2) 를 이용하여 $\mathrm{UCC}$ 간 유사도를 계산하고, 유사도 값이 높은 순으로 추천 레퍼런스 UCC 목록을 생성하게 된다.

$$
\begin{aligned}
& P\left(U_{a}, U_{i}\right)=\frac{\sum_{j=1}^{m}\left(d_{a, j}-\overline{d_{a}}\right)\left(d_{i, j}-\overline{d_{i}}\right)}{\sqrt{\sum_{i=1}^{m}\left(d_{a, j}-\overline{d_{a}}\right)^{2}} \sqrt{\sum_{i=1}^{m}\left(d_{i, j}-\overline{d_{i}}\right)^{2}}} \\
& \mathrm{~d}: \text { 레퍼런스 UCC의 UCC내 비율 } \\
& \mathrm{m}: \text { UCC내 일치하는 레퍼런스 UCC의 개수 } \\
& \mathrm{a}: \text { 제작자의 UCC } \\
& \mathrm{i}: \text { 타 제작자의 UCC } \\
& \mathrm{j}: \text { 레퍼런스 UCC }
\end{aligned}
$$

식 (1)은 목표 제작자와 타 제작자간 일치하는 선호 UCC 의 레퍼런스 UCC 목록을 이용해 UCC 간 유사도를 계산하 며, 유사도 계산은 피어슨 공식을 적용하였다. 식 (1)에서 나온 유사도는 식 (2)의 가중치로 사용된다.

추천 UCC 목록을 만들기 위한 가중치가 부여된 레퍼런 스 UCC 최종 유사도 공식은 식 (2)와 같다. 식 (2)에 의해 나온 최종 유사도를 정렬하여 유사도 값이 높은 $\mathrm{UCC}$ 의 레 퍼런스 $\mathrm{UCC}$ 를 제작자에게 추천하게 된다. 
표 2. UCC의 제작형태에 따른 분류

Table 2. Classification by production types of the UCC

\begin{tabular}{|c|c|c|c|c|c|}
\hline 분류 & 세분화 & 약어 & & 예 & 유형 \\
\hline \multirow{3}{*}{ 혈태 } & Generated & UGC & A & A가 고유한 창작에 의한 콘텐츠 & 순수장작룰 \\
\hline & Modified & UMC & $\begin{array}{l}A+a \\
=A\end{array}$ & $\begin{array}{l}\text { 소스콘텐츠 } \mathrm{A} \text { 에 사용자의 아이디어 } \mathrm{a} \text { 를 } \\
\text { 덧붙인 } \mathrm{A}^{\prime} \text { 는 } \mathrm{A} \text { 와 제작의도가 돟일함 }\end{array}$ & \multirow[b]{2}{*}{ 소스변혈물 } \\
\hline & Recreated & URC & $A+B=C$ & $\begin{array}{l}\text { 서로 다를 콘텐츠 } \mathrm{AB} \text { 를 조항하여 새로 } \\
\text { 운 콘텐츠 } \mathrm{C} \text { 가송성되었지만 제작의도 } \\
\text { 슨, } \mathrm{B} \text { 와 다른 고유한 아이디어로 이루 } \\
\text { 어짐 }\end{array}$ & \\
\hline
\end{tabular}

$$
\text { R.S. } U=\sum_{i=1}^{n}\left(S . U_{i}+P_{i}\right)
$$

R.S.U : 가중치가 부여된 Reference UCC 유사도

S.U : 제작자와 타 제작자간 일치하는 선호 UCC의 Reference UCC

$\mathrm{n}: \mathrm{UCC}$ 를 제작할 때 사용한 UCC의 개수

$a:$ 제작할 때 사용한 UCC

$\mathrm{p}:$ 피어슨 공식에 의한 유사도

\section{2. 레퍼런스 UCC 추천시스템을 위한 메타데이터} 요소 구성

본 논문에서 구성한 메타데이터 요소는 콘텐츠 관리를 위한 기능뿐만 아니라 UCC 제작형태, 저작권 보호, 추천시 스템에서 활용하기 위한 요소를 고려해야한다.

이를 위해 $\mathrm{UCC}$ 의 제작형태에 따른 분류를 알아볼 필요 성이 있다. $\mathrm{UCC}$ 의 제작형태는 $\mathrm{UGC}, \mathrm{UMC}, \mathrm{URC}$ 세 가지 분류로 나눠지며, 이를 다시 순수창작물과 소스콘텐츠를 이용한 변형물로 나눌 수 있다 ${ }^{[16][18]}$.

이를 바탕으로 $\mathrm{UCC}$ 의 저작케이스를 분석하면 그림 3 과 같다. 그림 3의 case- 1 은 하나의 UCC를 이용하여 다른 $\mathrm{UCC}$ 를 만드는데 활용한 케이스이며, $\mathrm{UCC}$ 를 만들기 위해
$\mathrm{UCC}$ 를 전체 삽입하는 케이스와 변환하여 삽입하는 케이 스, 일부 삽입하는 케이스로 나눠진다. 그림 3의 case-2는 두 개 이상의 $\mathrm{UCC}$ 를 이용하여 $\mathrm{UCC}$ 를 만드는 케이스이다. 2 개 이상의 $\mathrm{UCC}$ 를 합성해 새로운 $\mathrm{UCC}$ 를 만드는 케이스 와, 특정 부분만 합성하는 경우, 합성된 $\mathrm{UCC}$ 를 일부만 사 용하는 케이스로 다시 나눠지게 된다. 그림 3의 case-3은 $\mathrm{UCC}$ 콘텐츠의 음성 또는 영상만 활용하는 경우이다 ${ }^{[16]}$. 위와 같이 나눈 3 개의 케이스를 연결하면, 무수히 많은 케이스들이 다시 생성 되게 된다.

본 논문에서 제안하는 UCC 제작자를 위한 추천시스템 에서 활용하기 위해선 $\mathrm{UCC}$ 를 제작할 때 활용한 $\mathrm{UCC}$ 들의 정보가 필요하며, 이를 위해 가장 최초로 활용한 $\mathrm{UCC}$ 까지 찾으려면 위에서 도출된 임의의 케이스들에 관한 또 다른 변수들과 수많은 경우의 수를 고려해야 하기 때문에 매우 비효율적이라 할 수 있다. 이에 본 논문에선 레퍼런스 요소 를 추가하고 이를 이용해 제작할 때 활용한 상위 $\mathrm{UCC}$ 의 메타데이터만 명시해 놓음으로 그림 4 와 같이 제작할 때 활용한 $\mathrm{UCC}$ 를 찾아올라 갈 수 있도록 하여 저작권문제를 해결하고, 본 연구에서 제안하는 추천시스템에서 활용하고
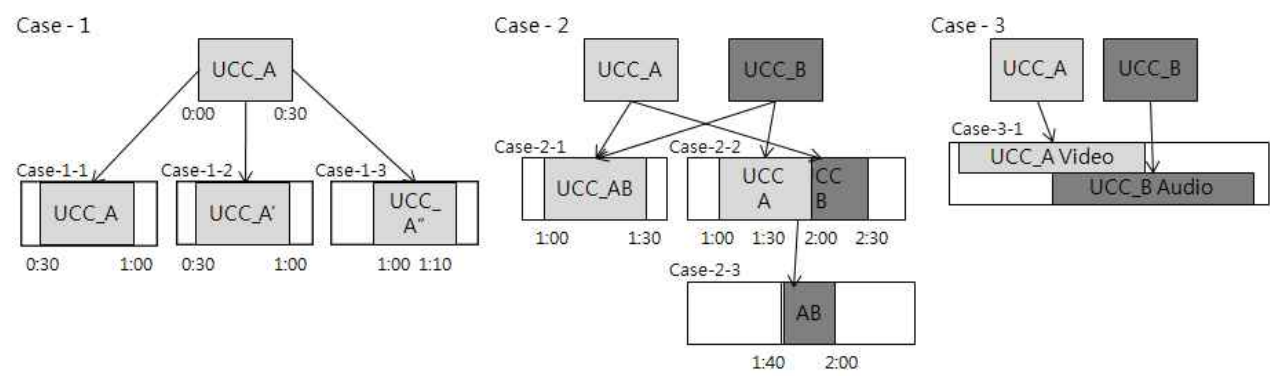

그림 3. UCC의 제작형태에 따른 케이스 분석pe

Fig. 3. The case analysis of production forms of the UCC 
자 하였다 ${ }^{[16]}$.

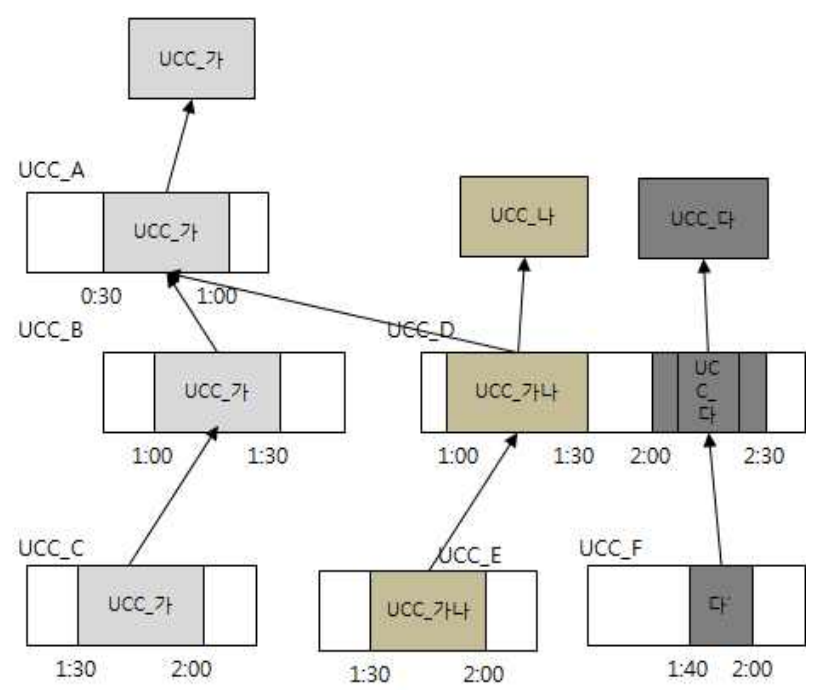

그림 4. 레퍼런스 요소를 이용한 상위 UCC 검색

Fig. 4. Parents UCC search by reference element

레퍼런스 요소는 하위요소로 identifier, startTime, duration을 가지고 있다 ${ }^{[17]}$.

identifier에는 레퍼런스 한 UCC 콘텐츠의 식별자이며, startTime은 제작된 UCC 콘텐츠에서 활용된 UCC가 시작 되는 시간, duration은 제작된 $\mathrm{UCC}$ 콘텐츠에서 활용된 $\mathrm{UCC}$ 의 진행시간을 명시해준다.

레퍼런스요소의 활용방법은 다음과 같다.

(1) UCC의 특정 부분을 활용하는 하는 경우, 활용된 $\mathrm{UCC}$ 의 식별자와 정보들을 제작된 $\mathrm{UCC}$ 의 레퍼런스 요소에 기록한다.

(2) 기록된 레퍼런스 요소는 제작자를 위한 추천시스템에 서 활용 하게 된다.

identifier의 레퍼런스를 이용해 레퍼런스 한 소스를 알 수 있고, startTime와 duration을 이용해, 제작물이 어떠한 타임에, 어떠한 소스가 사용되었는지 확인 할 수가 있다.

본 논문에서 활용하기 위한 메타데이터는 위에서 구성한 레퍼런스 요소와 UCI의 메타데이터를 활용하여 다음과 같 이 메타데이터를 구성되었다. 기본적인 콘텐츠 관리를 위
UCCA

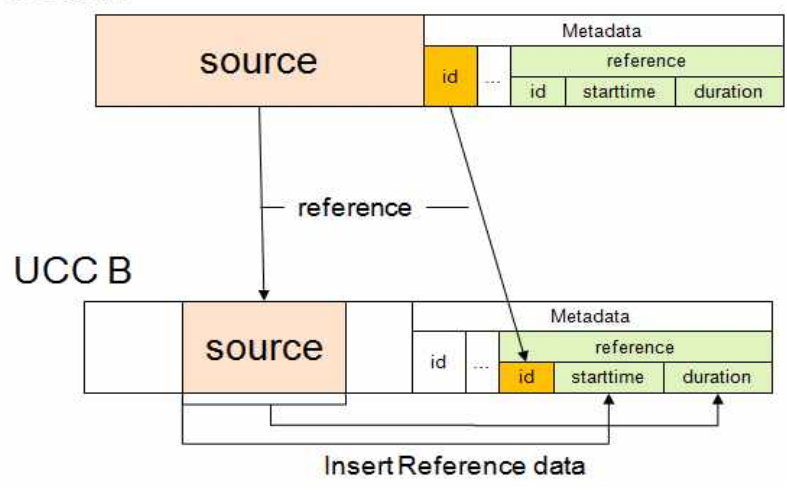

그림 5. 레퍼런스 요소를 이용한 Metadata의 원리

Fig. 5. The principles of Metadata by reference element

해 제공되는 메타데이터 요소들을 이용하여 총 14 개의 메 타데이터 요소- Title, Identifier, Description, Genre, Tag, Language, CreationDate, ProgramRef, FileFormat, Creator, MediaDuration, Relation, Rights, Reference- 로 이루어져 있다.

각 메타데이터 요소 별 세부 사항은 표 3과 같다.

표 3. 추천 시스템에서 활용하기 위한 메타데이터 요소미

Table 3. Metadata elements for use in the recommender System

\begin{tabular}{|c|c|l|}
\hline & 용어명 & \multicolumn{1}{|c|}{ 정의 } \\
\hline 1 & Title & UCC의 제목 \\
\hline 2 & Idetifier & UCC의 유일한 전역 식별자 \\
\hline 3 & Description & UCC에 대한 부가 설명 \\
\hline 4 & Genre & UCC이 속하는 장르 \\
\hline 5 & Tag & UCC를 나타내는 특정 단어 \\
\hline 6 & Language & UCC의 주 사용 언어 \\
\hline 7 & CreationDate & UCC의 생성일자 \\
\hline 8 & ProgramRef & UCC의 인스턴스를 가르키는 참조 식별자 \\
\hline 9 & FileFormat & UCC를 이루는 파일 포맷 \\
\hline 10 & Creator & UCC제작자 \\
\hline 11 & MediaDuration & UCC유효 기간, 유효 범위 \\
\hline 12 & Relation & UCC와 관련된 기타 정보 (URL, URI 등) \\
\hline 13 & Rights & UCC저작권 \\
\hline 14 & Reference & UCC에 기여 및 공헌한 참조 아이템/아이템 제작자 \\
\hline
\end{tabular}

\section{UCC 추천 시스템의 구성안}

그림 6 은 본 연구의 메타데이터 요소를 바탕으로 구성한 레퍼런스 UCC 추천 시스템이다. 이를 Reference UCC 
Recommender System이라 하였으며, 크게 User-created UCC check, Metadata check, Group by tag, Reference check, Reference calculator, Referenced UCC List로 나누 어진다. 각각의 기능은 다음과 같다 ${ }^{[19]}$.

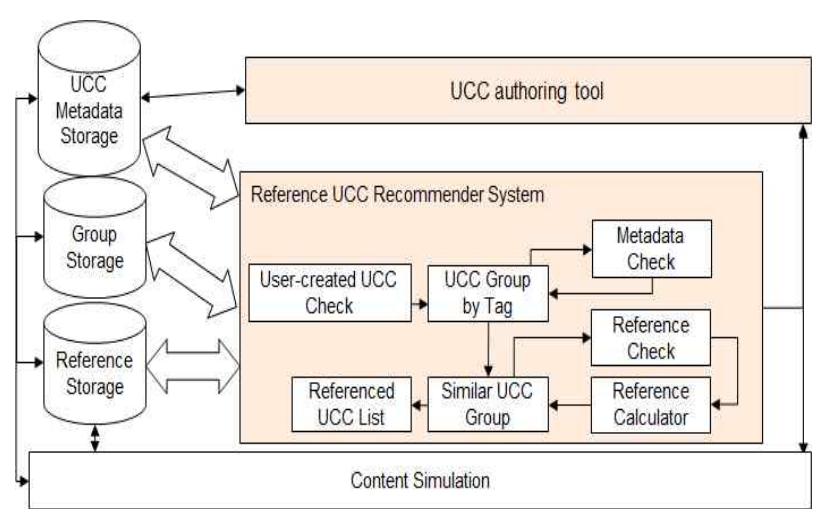

그림 6. 레퍼런스 UCC 추천 시스템의 구성안

Fig. 6. The composition of Reference UCC Recommender System

User-created UCC Check 에선 UCC Metadata Storage에 서 목표 $\mathrm{UCC}$ 제작자가 제작한 $\mathrm{UCC}$ 들을 확인하여 제작자
기반의 UCC 1 차 그룹군을 생성해낸다.

이를 위해 $\mathrm{UCC}$ 제작자의 유효성을 검증하고, $\mathrm{UCC}$ 제 작자가 제작한 UCC 콘텐츠 그룹을 확인 및 불러오게 된다. 세부 내용은 표 4 와 같다.

Group by Tag 에선 제작자 기반의 1차 그룹군을 타 제작 자 기반의 2 차 그룹군으로 확장한다. 2 차 그룹군은 태그를 고려하였기 때문에 사용자와 유사하면서도 연관성 높은 그 룹이라 볼 수 있다. UCC Metadata Storage로부터 도출된 2차 그룹군은 Group Storage에 저장되며, 동일한 프로세스 진행시 불필요한 연산을 줄이기 위해 활용된다. 세부내용 은 표 5 와 같다.

Metadata Check 에선 1차 그룹군으로 생성된 $\mathrm{UCC}$ 들의 메타데이터를 확인한다. 추천시스템에서 1차 그룹군으로 확인되는 메타데이터는 태그요소이며, 확인된 태그들은 Group by Tag에서 활용된다. 세부내용은 표 6과 같다.

Similar UCC Group는 2차 그룹군을 추려 사용자와 가장 유사한 3 차 $\mathrm{UCC}$ 그룹군을 도출해내는 단계이다. 유사한 $\mathrm{UCC}$ 도출을 위해 제작자와 타제작자가 제작한 UCC 간의 유사도를 이용해 3 차 $\mathrm{UCC}$ 그룹군을 도출한다. 이를 위해

표 5. Group by Tag의 Process

Table 5. Process of Group by Tag

\begin{tabular}{|c|c|}
\hline Name & Description \\
\hline Content.setContentGroup(ContentGroup) & UCC 그룹군의 유효성 검증 \\
\hline $\begin{array}{c}\text { Content.getContentGroup } \\
\text { return ContentGroup; }\end{array}$ & UCC 그룹군의 정보 반환 \\
\hline GbT.setCreatedUCC(ContentgetContentGroup) & UCC 그룹군의 속성값 지정 \\
\hline GbT.Group_by_Tag() & UCC 그룹군을 선호기반 태그로 그룹화 \\
\hline DB.GroupStorage(prefer_Content_Group) & UCC 그룹군을 GroupStorage에 저장 \\
\hline $\begin{array}{c}\text { GbT.getCreatedUCC() } \\
\text { return prefer_Content_Group; }\end{array}$ & 목표 UCC 제작자가 제작한 UCC 그룹 반환 \\
\hline
\end{tabular}

표 6. Metadata Check의 Process

Table 6. Process of Metadata Check

\begin{tabular}{|c|c|}
\hline Name & Description \\
\hline Content.setContent(Content) & UCC의 유효성 검증 \\
\hline $\begin{array}{c}\text { Content.getContent } \\
\text { return Content; }\end{array}$ & UCC의 정보 반환 \\
\hline MC.setLoad_ContentMetadata(Content) & UCC의 속성값 지정 \\
\hline MC.Load_ContetMetadata() & UCC Metadata Storage에서 UCC의 메타데이터 불러오기 \\
\hline $\begin{array}{c}\text { MC.getLoad_ContentMetadata() } \\
\text { return ContentMetadata; }\end{array}$ & 불러온 UCC의 메타데이터 반환 \\
\hline
\end{tabular}


Reference Check 모듈과 Reference Calculator 모듈과 연계 된다. 세부 내용은 표 7과 같다.

Reference Check에선 원 제작자 기반의 1 차 그룹군과 타 제작자 기반의 2 차 그룹군의 레퍼런스 데이터를 비교해 공 통으로 제작할 때 활용한 $\mathrm{UCC}$ 의 레퍼런스 데이터를 Reference Calculator로 보낸다. 이를 위해 레퍼런스 UCC 의 데이터를 Reference $\mathrm{DB}$ 에서 불러오며, 불러온 데이터를
비교하게 된다. 상세 내용은 표 8과 같다.

Reference Calculator에선 이 데이터를 이용해 UCC 제작 자의 레퍼런스 $\mathrm{UCC}$ 와 타 $\mathrm{UCC}$ 제작자의 레퍼런스 $\mathrm{UCC}$ 간 유사도를 계산한다. 우선 $\mathrm{UCC}$ 제작자와 타 $\mathrm{UCC}$ 제작 자간에 일치 하는 레퍼런스 $\mathrm{UCC}$ 들의 목록을 추린 후, 각각 의 $\mathrm{UCC}$ 가 제작된 $\mathrm{UCC}$ 에서 차지하는 비율을 피어슨 공식 에 대입하여 UCC 간의 유사도를 구한다. 상세내용은 표

표 7. Similar UCC Group의 Process

Table 7. Process of Similar UCC Group

\begin{tabular}{|c|c|}
\hline Name & Description \\
\hline SUG.setSimilar_UCC_Group(ContentGroup) & 유사 UCC 그룹의 속성값 지정 \\
\hline SUG.Similar_UCC_Group() & $\begin{array}{c}\text { 제작자와 타제작자가 제작한 UCC 간의 유사도를 이용해 } \\
\text { 3차 UCC 그룹군을 도출 }\end{array}$ \\
\hline $\begin{array}{l}\text { SUG.getSimilar_UCC_Group() } \\
\text { return Similar_UCC_Group; }\end{array}$ & 도출된 유사 UCC 그룹 반환 \\
\hline
\end{tabular}

표 8. Reference Check의 Process

Table 8. Process of Reference Check

\begin{tabular}{|c|c|}
\hline Name & Description \\
\hline Content.setContent(Content) & $\mathrm{UCC}$ 의 유효성 검증 \\
\hline $\begin{array}{l}\text { Content.getContent() } \\
\text { return Contet; }\end{array}$ & UCC의 정보 반환 \\
\hline RC.setLoad_reference_data(Content) & 제작시 활용된 UCC 알아내기 위한 UCC 속성값 지정 \\
\hline RC.Load_reference_data() & 제작시 활용된 UCC의 reference data 불러오기 \\
\hline $\begin{array}{l}\text { RC.getLoad_reference_data() } \\
\text { return referencedata; }\end{array}$ & 제작시 활용된 UCC의 reference data값 반환 \\
\hline $\begin{array}{l}\text { RC.setCheck_reference_data } \\
\text { (RC1.reference_data,RC2.reference_data) }\end{array}$ & $\begin{array}{c}\text { 목표 제작자의 제작할 때 활용한 UCC와 타 제작자의 제작할 때 활용한 } \\
\text { UCC를 속성값으로 지정 }\end{array}$ \\
\hline RC.Check_reference_data() & $\begin{array}{c}\text { 목표 제작자의 제작할 때 활용한 UCC와 타 제작자의 제작할 때 활용한 } \\
\text { UCC가 일치되는지 체크하며, 일치 된다면 } \\
\text { 유사도 계산과정으로 넘어가게 됨. }\end{array}$ \\
\hline $\begin{array}{l}\text { GbT.getCheck_reference_data() } \\
\text { return Content_MatchreferenceContent; }\end{array}$ & $\begin{array}{c}\text { 목표 제작자의 제작할 때 활용한 UCC와 타 제작자의 제작할 때 활용한 } \\
\text { UCC를 비교해서 값이 일치하는 제작 된 UCC 반환 }\end{array}$ \\
\hline
\end{tabular}

표 9. Reference Calculator의 Process

Table 9. Process of Reference Calculator

\begin{tabular}{|c|c|}
\hline Name & Description \\
\hline $\begin{array}{c}\text { Content.setMatchreferenceContent } \\
\text { (Content_MatchreferenceContent;) }\end{array}$ & 일치하는 UCC들의 제작시 활용된 \\
UCC 유효성 검증 \\
\hline $\begin{array}{c}\text { Content.getMatchreferenceContent() } \\
\text { return Content_MatchreferenceContent; }\end{array}$ & 유효성이 검된 UCC 반환 \\
\hline RCal.setreference_caculator(MatchreferenceContent) & UCC 간의 유사도 계산을 위해 일치하는 UCC 요소 지정 \\
\hline RCal.reference_caculator() & UCC 간 유사도 계산 \\
\hline $\begin{array}{c}\text { RCal.getreference_caculator() } \\
\text { return SimilarityScore }\end{array}$ & $\begin{array}{c}\text { 목표 제작자가 제작한 UCC와 타 제작자가 } \\
\text { 제작한 UCC간의 유사도 반환 }\end{array}$ \\
\hline
\end{tabular}


표 10. Reference UCC List의 Process

Table 10. Process of reference UCC List

\begin{tabular}{|c|c|}
\hline Name & Description \\
\hline RUL.setReference UCC_List & 1차 그룹군과 3차 그룹군 비교를 위한 각 그룹 요소 지정 \\
(user_CreatedUCC_Group,Similar_UCC_Group) & 제작자가 활용하지 않은 UCC 체크 및 그룹화 \\
\hline RUL.Content.Reference UCC List() & 제작자가 활용하지 않은 UCC 그룹군 반환 \\
\hline RUL.getReference UCC List() & 우선 순위 정렬을 위한 UCC 리스트 요소 지정 \\
\hline RUL.setReference SortUCC List(UCC List) & 활용빈도 기반의 UCC 리스트 우선순위 정렬 \\
\hline RUL.Reference SortUCC List() & 추천리스트 반환 \\
\hline $\begin{array}{c}\text { RUL.getReference SortUCC List() } \\
\text { retrun Recommend_UCC_List }\end{array}$ &
\end{tabular}

9와 같다.

Referenced UCC List에선 UCC와 유사한 UCC 그룹에 서 추천리스트를 생성, 추천하는 단계이다. 추천리스트는 1 차 그룹을 제작할 때 활용한 $\mathrm{UCC}$ 와 3 차 그룹을 제작할 때 활용한 UCC들을 비교하여, 제작자가 제작할 때 활용하지 않은 UCC 중 제작할 때 활용빈도가 가장 높은 것들을 우선 순위로 정렬하여 추천하게 된다. 상세 내용은 표10과 같다.

\section{IV. 결 론}

$\mathrm{UCC}$ 제작자들에겐 $\mathrm{UCC}$ 를 소비하는 사용자들과는 차 별화된 별도의 추천 시스템이 필요하다. 이를 위해 본 논문 에선 UCC 제작자의 정보와 제작할 때 이용한 콘텐츠에 관한 정보를 추천 시스템에서 활용하였으며, 이를 통해 $\mathrm{UCC}$ 제작자들을 고려한 추천 서비스를 제공할 수 있도록 하였다.

본 논문에선 $\mathrm{UCC}$ 를 제작할 때 활용한 $\mathrm{UCC}$ 의 정보를 담 을 수 있도록 메타데이터 요소에 레퍼런스 요소를 추가하 였다. 또한 레퍼런스의 하위 요소인 identifiter, startime, duration 요소를 별도로 구성하였다. 이 하위 요소들은 본 추 천 시스템의 협업 필터링 알고리즘에서 주요 계산 요소로 활용하였다.

추천 시스템은 협업필터링 알고리즘을 이용하여 UCC간 의 유사도를 계산함으로써, 추천 시스템의 신뢰성과 효율 성을 높이고자 하였다. 또한 제작할 때 활용한 $\mathrm{UCC}$ 의 정보 가 담긴 메타데이터의 요소들을 유사도 계산에 이용함으로 써, $\mathrm{UCC}$ 제작자와 유사도가 높은 $\mathrm{UCC}$ 를 우선적으로 선별
하여 추천 할 수 있도록 하였다.

본 논문에서 제안하는 추천 시스템은 향후 프로토타입 구현 및 데이터 수집 과정을 통해 알고리즘의 검증 및 최적 화 단계를 거칠 것이다. 이로 인해 UCC 제작자는 보다 효 율적이고 편이성 높은 제작자 맞춤형 UCC 추천 서비스를 제공 받을 수 있을 것이며, 레퍼런스 요소를 활용하여 제작 할 때 활용한 콘텐츠에 관한 정보와 제작자의 정보를 명시 해 줌으로써, 저작권 문제 또한 해결 할 수 있을 것이라 기 대한다.

\section{참 고 문 헌}

[1] 김문형 외, UCC 의 동향 및 전망, IITA 기술정책자문단, 2006

[2] 홍효진, 컨버전스 시대의 디지털 콘텐츠 시장, NCA ISSUE REPORT NO.06-12

[3] 오정민, 글로벌 웹 콘텐츠의 문화 특성 연구 - 한국, 미국, 일본, 중국 4개국 을 중심으로, 한국컴퓨터정보학회 논문지, 제 15 권, 제 3 호, pp.45-53, 2010.3

[4] 윤종수, UCC 저작권의 차별적 취급과 보상체제 - UCC 시대의 저작권 패 러다임의 변화와 대안적 논의들을 중심으로 ‘ 저스티스」, 통권제106호6, pp.426-461, 2008.9

[5] 조영복, 웹 콘텐츠 저작권 보호를 제공하는 통합 메타데이터 기반의 다중 $\mathrm{CMS}$ 시스템, 한국통신학회논문지, 2008

[6] 변재희, 김경록, 김형환, 문남미, 모바일 UCC 서비스를 위한 최적화 카테 고리 설계, 한국방송공학회 2010 하계학술대회, 2010. 7

[7] 윤승욱, 모바일 시대에서의 모바일 UCC 활성화 가능성 모색, 동서온론, 제11집, pp.329-364, 2008.2

[8] 이동주, 이상근, 이상구, 시간 상황 정보를 고려한 협업 필터링을 이용한 음악 추천, 한국정보과학회 2009 한국컴퓨터종합학술대회 논문집, 제 36 권, 제 1호(C), pp. 123-128, 2009

[9] Gediminas Adomavicius, Alexander Tuzhilin, Toward the Next Generation of Recommender System : A Survey of the State-of-the-Art and Possible Extension, IEEE Transactions on Knowledge and Data Engineering, Vol. 17, No. 6, pp. 734-749, June 2005

[10] 토비 세가란 저, 윤종완 역, 집단지성 프로그래밍, 한빛미디어(주), 서울, 
pp.20-28, 2008

[11] Kyung-Rog Kim, Ju-Ho Lee, Jae-Hee Byeon, Nam-Mee Moon, Recommender System Using the Movie Genre Similarity in Mobile Service, The 4th International Conference on Multimedia and Ubiquitous Engineering, 2010

[12] Jung-Min Oh, Ju-Hong Song, Nam-Mee Noon, Preference Element Selectable Interactive Recommender System by Employing Collaborative Filtering, The 4th International Conference on Multimedia and Ubiquitous Engineering, 2010

[13] 김효원, 이미지 콘텐츠에 대한 메타데이터와 디지털 아카이브 구축 방안 연구, 숙명여자대학교 대학원, 석사학위 논문, pp.7-10, 2009
[14] 김진아, 김태수, 동영상 정보의 메타데이터 구축에 관한 연구, 한국정보관 리학회지, 제 18 권, 제 4 호, 통권 제 42 호, pp.15-35, 2001

[15] 이혜규, 개인화된 방송 컨텐츠의 효율적 브라우징을 위한 메타데이터 검 색 구조 설계, 한양대학교 대학원, 석사학위 논문, pp.4-10, 2009.2

[16] 송주홍, 이은미, 문남미, History를 검색하기 위한 Learning UCC 메타데 이터 Reference 모델 설계, 2009 한국방송공학회 학술대회 논문집, pp.399-402, 2009.11

[17] http://www.uci.or.kr

[18] 마케팅사관학교\&김영환, You! UCC, 랜덤하우스, p.30, 2007.2

[19] 송주홍, 홍인화, 김찬규, 문남미, 참조된 콘텐츠를 위한 UCC 추천 시스템 설계, 2010 한국방송공학회 추계 학술대회 논문집, 2010.11

저 자 소 개

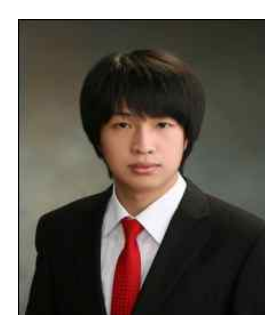

\section{송 주 홍}

- 2010년 2월 호서대학교 컴퓨터공학과/뉴미디어학과 (공학사)

- 현재 : 호서벤처전문대학원 IT 응용기술학과 석사과정

- 주관심분야 : Social, 추천 시스템, 개인화 서비스, 메타데이터

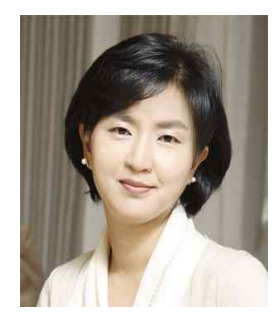

\section{문 남 미}

- 1985년 2월 : 이화여자대학교 컴퓨터학과 (공학사)

- 1987년 2월 : 이화여자대학교대학원 컴퓨터학과 (공학석사)

- 1998년 2월 : 이화여자대학교대학원 컴퓨터학과 (공학박사)

- 1999년 2003년 : 이화여자대학교 조교수

- 2004년 2008년 : 서울벤처전문대학원 IT 응용기술학과 교수

- 2008년 현재 : 호서대학교 벤처전문대학원 IT 응용기술학과 교수

- 주관심분야 : 디지털데이터방송비즈니스 모델, $\mathrm{HCl}, \mathrm{T}$-Commerce, 메타데이터 